\title{
AN EFFECT OF THE RECIPE COMPOSITION ON MINCED MEAT PROPERTIES
}

Received 23.02.2021

Accepted in revised 18.06.2021 Accepted for publication 25.06.2021

\author{
Elena. V. Tsaregorodtseva \\ Mari State University, Yoshkar-Ola, Russia
}

\begin{abstract}
Keywords: by-products, broiler chickens, chicken muscles, milk fat, ginger, oxidative stability, water holding capacity
Abstract

The paper describes an experiment on the development of minced meat recipes for poultry-based semi-prepared products. The design principle included a search for optimal compatibility of recipe ingredients to develop a balanced meat system. The model recipes included meat from different animal and poultry species, by-products and dairy products. White and red turkey meat and chicken breast fillet provided recipes with complete animal proteins. Fat meat raw materials were partly replaced with milk fat. A semi-prepared product filled into an intestinal casing was named "sausages for grilling". A technology of sausages for grilling was developed with the indication of the main control technological parameters for the production process and thermal treatment up to product readiness. The incoming control of raw material quality was carried out: dairy cream was assessed by acidity and pasteurization effectiveness; cheese by sensory indicators; meat raw materials by the pH value. The functional-technological properties of raw minced meat for sausages for grilling were compared before and after cooking by the $\mathrm{pH}$ level, moisture mass fraction, water binding capacity. The rheological properties of minced meat (adhesion, viscosity, shearing structural-mechanical properties) were studied. The expedience of introducing meat by-products and dairy ingredients into recipes of sausages for grilling to stabilize protein and fat in the meat system was substantiated. It was proved that replacement of the main raw materials in recipes with pork heart, ginger, cheese and chicken liver allows obtaining sausages for grilling with preservation of high quality indicators. Sausage sensory properties after grilling were analyzed.
\end{abstract}

\section{Introduction}

Historically, meat has been an important part of the typical human diet being an important source of macroand micronutrients, including protein, fat, iron, selenium, folic acid, zinc and vitamins $A$ and $B_{12}$. According to the FAO forecasts, global meat production should additionally grow by 200 million tons by 2050 to correspond to the current forecasts for food demand [1].

Meat product manufacturers include simultaneously different types of animal and poultry meat into most minced meat recipes. Beef, pork, chicken and turkey meat, mutton and horse meat can have different weight proportions in the matrices of mixed minced meat, which gives an opportunity to produce meat systems balanced by the chemical composition and having different nutritional values [2]. A wide assortment of minced semi-finished products can be seen in retail display cases. These products are more often produced from pork and, consequently, contain significant amounts of intermuscular fat and speck, which is not recommended for people adhering to the healthy life style, as well as for people having problems with the digestive tract and cardiovascular system including atherosclerosis. A solution to this problem consists in the development of poultry-based semi-finished products with the moderate caloricity and high protein content [3].

Over the last years, changes in the food composition have been actively studied. The available base and different methods for recipe changes allow affecting the food profile and create high-quality products that are acceptable, prepared in a simple and economical way, correspond to the food legislation and are suitable for using in the industrial scale [4].

The perception of foods as wholesome is an important factor influencing food behavior of people that are prone to consciously restrict their nutrition to control appetite or weight [5]. Over the last years, researchers and the meat industry focused upon the development of lowfat meat products. However, meat products with low fat content (10\% or lower) are tougher, less juicy and flavory, darker, expensive and less acceptable than their analogs with higher fat content [6]. One of the options for producing minced meat for semi-finished products balanced by the chemical composition is introduction of turkey meat having functional properties [7] and turkey by-products [8] into recipes. Turkey meat has lower fat content and higher protein content than pork. Therefore, sausage meat that contains turkey meat can be the healthier solution compared to meat from other animal and poultry species [9]. The protein and fat content in turkey meat is $25 \%$ and $4 \%$, respectively. Broiler chicken meat protein contains $92 \%$ of amino acids necessary for humans. The content of lipids in broiler chicken meat is about $11 \%$ and many of them are unsaturated. These peculiarities of the fatty acid composition of poultry fats determine the low 
temperature of their melting (lower than $40{ }^{\circ} \mathrm{C}$ ), which ensures their good emulsifying capacity and assimilability by the human body [10]. Fat plays an important role in the development of the desired texture of meat products. The mass fraction of animal fats in a minced meat recipe can be regulated by the use of fats from dairy products [11]. Dairy cream imparts good technological properties to meat systems [12]. The protein composition of dairy cream, stability of fat globules and their resistance to agglomeration are influenced by thermal treatment. Pasteurized dairy cream has more stable fat globules and, therefore, is preferable for using in meat systems [13]. Addition of dairy cream with the increased fat content into recipes enables improving structural-mechanical properties, creating necessary consistency and harmonious taste of meat products [14].

Cheese, a dairy product produced by different methods, is often used in meat product technology providing multiple characteristics such as the unique taste, texture and aroma [15]. Semi-hard cheeses introduced into meat systems are distinguished by low moisture content, firm consistency and flavory, strong taste. These cheese characteristics are taken into account when developing multicomponent recipes [16].

To improve physico-chemical properties and sensory characteristics, plant raw materials [17] and dietary fibers [18] are introduced into minced meat. The use of the dry ginger powder in meat product recipes allows extending shelf-life. The expediency of using ginger for increasing safety and controlling microbial growth in chicken meat was proved. Fermented ginger paste causes reduction of $\mathrm{pH}$ in chicken meat from 5.66 to 4.73 and moisture content from $76 \%$ to $72 \%$. The paste from fermented ginger can control the growth of spoilage microorganisms and demonstrates the high potential for the large-scale industrial application in manufacturing products from chicken meat [19]. It was shown that ginger can be considered a potential replacement of nitrite both for color formation and for inhibition of the growth of Escherichia coli, Staphylococcus and Salmonella in meat products. Addition of ginger into recipes decreases an amount of nitrite in meat products without meat safety impairment. Compared to nitrite, ginger has additional functional advantages: the nutritional value and absence of toxicity when working with it [20].

Spices and herbs with the bactericidal action are introduced into minced meat. The use of rosemary, garlic, onion, pepper (black, red, Sichuan, chili), sage, lemon and others in meat products is well known. Spices and herbs have the antioxidant activity. For example, they reduce oxidative stress or inhibit oxidation of meat components during processing. Many researchers revealed interaction between a decrease in formation of potential carcinogenic substances and antioxidant properties of spices and herbs [21,22].
The aim of the study was to develop recipes and technologies for mixed minced meat from different types of meat raw materials and dairy products. Addition into minced meat recipes of pork, by-products, dairy ingredients instead of chicken skin confirmed the hypothesis about preservation of functional properties in minced meat and achievement of high sensory characteristics in the finished product. The obtained information can be used to determine product strengths compared to analogs. Comparison of functional-technological properties of experimental minced meat and finished products allows evaluating and revealing ways for improving sensory properties that influence consumer preferences.

\section{Objects and methods}

The recipe development, production and quality assessment of samples of sausages for grilling were carried out in the Department of Meat and Dairy Product Technology according to the scheme presented in Figure 1.

The composition of the minced meat recipes under development is presented in Table 1. The following main raw materials were used in the recipes: broiler chicken meat and chicken skin, turkey meat, pork heart, chicken liver, pork belly and speck, semi-hard cheese, dairy cream with $20 \%$ fat. The auxiliary materials included fresh garlic, edible salt, sugar, ground white pepper, cardamom, ground ginger, ground paprika. The recipes of the model minced meat are presented in Table 1.

At the stage of mixing, $20 \%$ of drinkable water and 1 $\mathrm{kg}$ of salt per $100 \mathrm{~kg}$ of the main raw materials were added for preliminarily salting. Water addition was not envisaged by the recipe of the control sample according the technical specifications for the product. Part of garlic and sugar was replaced with ground cardamom, ginger and paprika in the recipes of the samples. Spices were not used in the control sample recipe; garlic was added in an amount of $2 \%$ of the main raw material weight.

The basis of the meat constituent in the control sample recipe was white meat of broiler chicken breast fillets $(50 \%)$ and red meat of turkey thigh (38\%). In sample No. 1, broiler chicken breast fillets were replaced with pork heart in an amount of $10 \%$, the volume of meat from turkey thigh was reduced by $8 \%$ and chicken skin was completely removed from the recipe replacing it with pork belly (17\%). Chicken skin was replaced with ingredients containing easily assimilable animal fats in all experimental samples. Skin was replaced with pork speck in sample No.2, with cheese in sample No.3 and partly with pork belly and chicken liver in sample No.4. To impart juiciness and tenderness to the finished product, dairy cream was added into the model sausage meat in samples No.1, No.2, No. 3 in an amount of $3 \%$ instead of broiler chicken breast fillets. Sausages were stuffed into natural casings (pig small intestines). 


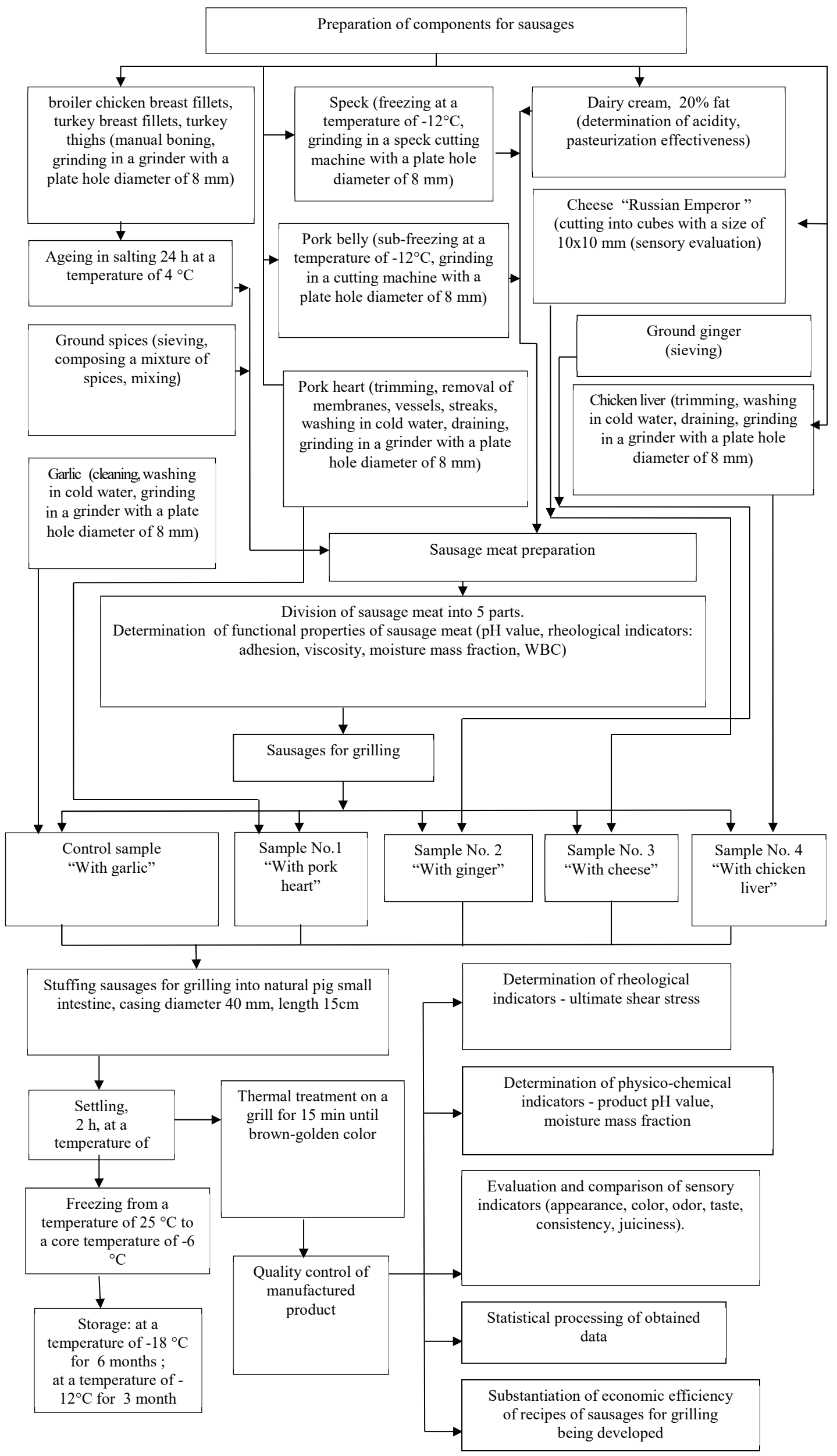

Figure 1. Scheme of the experimental investigations 
Table 1. Recipes of minced meat for sausages for grilling

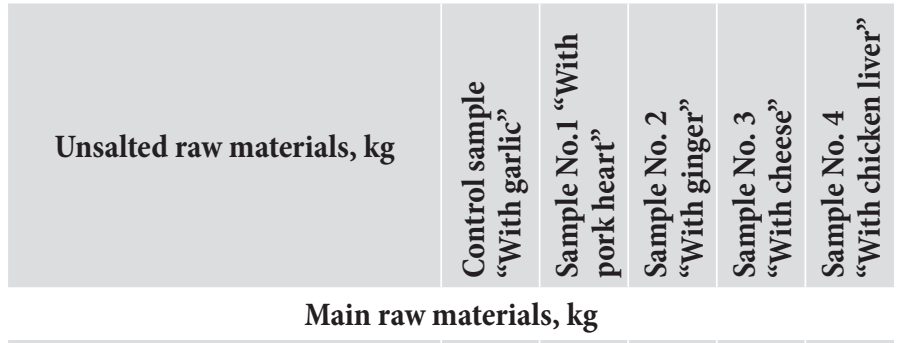

\begin{tabular}{|l|c|c|c|c|c|}
\hline Broiler chicken breast fillets & 50 & 40 & 40 & 45 & 40 \\
\hline Turkey breast fillets (white meat) & - & - & 40 & - & 25 \\
\hline Turkey thighs (red meat) & 38 & 30 & - & 35 & - \\
\hline Chicken skin & 12 & - & - & - & - \\
\hline Pork heart & - & 10 & - & - & - \\
\hline Chicken liver & - & - & - & - & 15 \\
\hline Pork speck & - & - & 17 & - & - \\
\hline Pork belly & - & 17 & - & - & 20 \\
\hline Semi-hard cheese & - & - & - & 17 & - \\
\hline Drinkable dairy cream, 20\% fat & & 3 & 3 & 3 & - \\
\hline TOTAL & 100 & 100 & 100 & 100 & 100 \\
\hline \multicolumn{1}{|c|}{ Spices and herbs per 100 kg of unsalted raw materials, kg } \\
\hline Fresh garlic & 2 & 0,4 & 0,6 & 0,2 & 0,4 \\
\hline Edible salt & 1 & 1 & 1 & 1 & 1 \\
\hline Granulated sugar & 0,25 & - & - & - & - \\
\hline Ground white pepper & 0,3 & 0,3 & 0,1 & 0,3 & 0,3 \\
\hline Cardamom & - & 0,3 & - & - & 0,3 \\
\hline Ground ginger & - & - & 0,5 & - & - \\
\hline Ground paprika & - & - & - & 0,3 & - \\
\hline Water, \% & - & 20 & 20 & 20 & 20 \\
\hline Yield, \% & 103.55 & 102 & 102.2 & 101.8 & 102 \\
\hline
\end{tabular}

To determine physico-chemical, structural-mechanical and other indicators of the initial raw materials, ingredients, minced meat and finished products, standard and modified analytic methods and equipment were used. Moisture mass fraction in minced meat and finished sausages was determined by the thermal gravimetric method using a drying apparatus APS-1 (Russia). With that, moisture mass fraction was calculated by the difference in the mass of the initial and dried samples. To determine $\mathrm{pH}$ of meat raw materials and minced meat, $\mathrm{pH}$-meter of the model 2696 (Russia) was used. A range of $\mathrm{pH}$ measurement was 0 to 14 , precision $0.02 \mathrm{pH}$ units. Minced meat viscosity was measured on the Brookfield viscometer RVDVE with RV 7 spindle (USA). A range of viscosity values was 100 to $13,000,000 \mathrm{mPa}^{*}$ s, rotational speed was 0.3 to $100 \mathrm{rpm}$. Viscosity was measured at $2 \mathrm{rpm}$. Shearing structural-mechanical properties of the finished product were measured on the laboratory conical plastometer CP-3 (Russia). Detection limit for ultimate shear stress was up to $1 \mathrm{MPa}$. The adhesion level was determined on the unit for stickiness measurement by S. Tishkevich. Water binding capacity (WBC) of minced meat was determined by the pressing method and then by calculation. Sensory evalu- ation of finished products after grilling was carried out by the descriptive (profile) method. Cream acidity was determined by the titrimetric method ${ }^{1}$, pasteurization effectiveness by the peroxidase reaction ${ }^{2}$. Cheese quality was assessed by appearance of a cheese wheel, consistency, taste and odor, color, pattern on the cut surface of the cheese ${ }^{3}$.

Statistical processing of the experimental results was carried out according to [24]. With that, the arithmetic mean and standard deviations were calculated. Then, for these samples, the standard error of the arithmetic mean deviations and limits of its confidence interval were determined with account for the Student's $t$-coefficient (n, $\mathrm{p})$ at the significance level of $95 \%(\mathrm{p}=0.05)$ and the number of measurements. Then, the significance of differences between mean values in the experimental and control samples were assessed by the $\mathrm{p}$-value in the variant of the two-sample unpaired t-test with uneven dispersions. Differences were considered significant when inequality $\mathrm{P} \geq 0.05$ was true.

\section{Results and discussion}

Dairy cream (20\% fat) was introduced into the model minced meat recipes in an amount of $3 \%$ of the main raw material mass. The incoming control of dairy cream acidity showed the level of $18^{\circ} \mathrm{T}$, which indicated their freshness and wholesomeness. When determining pasteurization effectiveness, a change in the color of the tube content was not noticed; therefore, peroxidase was broken down and dairy cream was pasteurized correctly at the high temperature.

The recipe of sample No.3 contained semi-hard cheese in an amount of $17 \%$ of the main raw material mass. When assessing appearance of a cheese wheel, the uniform and strong condition of the crust and paraffin layer was observed. Consistency was moderately elastic, homogeneous throughout the wheel. Taste and odor were cheesy, slightly acidic. The pattern on the cut surface consisted in eyes of the irregular and angular shape that were uniformly located throughout the cheese mass. The color was in a range from white to light yellow. Cheese did not pass its shelf life date and the product was made according to the requirements of the standard.

To classify meat raw materials according to quality groups, hydrogen ion concentrations in thigh and breast muscles were measured immediately after boning poultry carcasses.

Changes in the $\mathrm{pH}$ values demonstrate meat system stability and indicate the development of irreversible protein aggregates and the level of meat raw material ageing [25]. It was established that after slaughter the $\mathrm{pH}$ level dropped in

${ }^{1}$ GOST 3624-92 "Milk and milk products. Titrimetric methods of acidity determination". Moscow: IPK Standards Publishing House, 2004. - 8 p. (In Russian)

${ }^{2}$ GOST 3623-2015 "Milk and milk products. Methods for determination of pasteurization". Moscow: Standartinform, 2016. - 12 p. (In Russian)

${ }^{3}$ GOST 33630-2015 "Cheese and processed cheese. Methods for control of organoleptic properties”. Moscow: Standartinform, 2016. — 58 p. (In Russian) 
broiler meat (drumsticks) from the initial value of 6.18 to the ultimate value of 5.96 at 24 hours after slaughter [26]. For turkey meat, $\mathrm{pH}$ was 5.93 to 6.0 , and in turkey fillet 6.20 (normal) and 6.04 (pale) [27]. In the present study, the $\mathrm{pH}$ value in turkey meat was 5.94, in broiler chickens 5.96, which corresponds to the data of foreign scientists mentioned above. The indicators allow making a conclusion about classification of meat as the NOR quality group and the expediency of using poultry meat in the technology of sausages for grilling.

At the stage of minced meat preparation, the $\mathrm{pH}$ level was measured again, minced meat properties were analyzed (Figure 2).

Addition of dairy ingredients, by-products, ginger, salt and spices into the experimental minced meat samples did not influence changes in the $\mathrm{pH}$ level in raw minced meat. The significant difference between the samples by the level of hydrogen ion concentration was not revealed.

The rheological properties of meat systems are determined by the solubility of muscle protein, a size of minced meat particles, viscosity, capacity to bind water, fat and other minced meat constituents [28]. It was found in the rheo- logical investigation of minced meat (adhesive properties, Figure 3) that the highest adhesion level $(399.25 \pm 10.34)$ was in the control sample. Addition of water into minced meat led to a significant decrease in adhesion compared to the control. Addition of cheese into the recipe of sample No.3 facilitated maintenance of minced meat stickiness due to the content of milk fat in the cheese composition. With that, this indicator exceeded stickiness in samples No.1 and No.2 by $43.5 \mathrm{~Pa}$ and $34.25 \mathrm{~Pa}(\mathrm{P}<0.01)$, respectively. The lowest adhesion level was in sample No.1. This means that addition of pork heart into minced meat insignificantly reduces minced meat stickiness, and crumbly texture of the product is possible after thermal treatment.

In terms of rheological properties, structural rigidity and viscosity of raw minced meat play an important role in assurance of the right texture and consistency of the finished meat product. High viscosity of chicken-based minced meat ensures safe consistency of the finished product and can delay the rate of flow for food bolus during swallowing [29]. Absence of water in the recipe of the control sample also determined the high level of minced meat viscosity $(532.40 \pm 37.16 \mathrm{~Pa} \cdot \mathrm{s})$ and strong minced

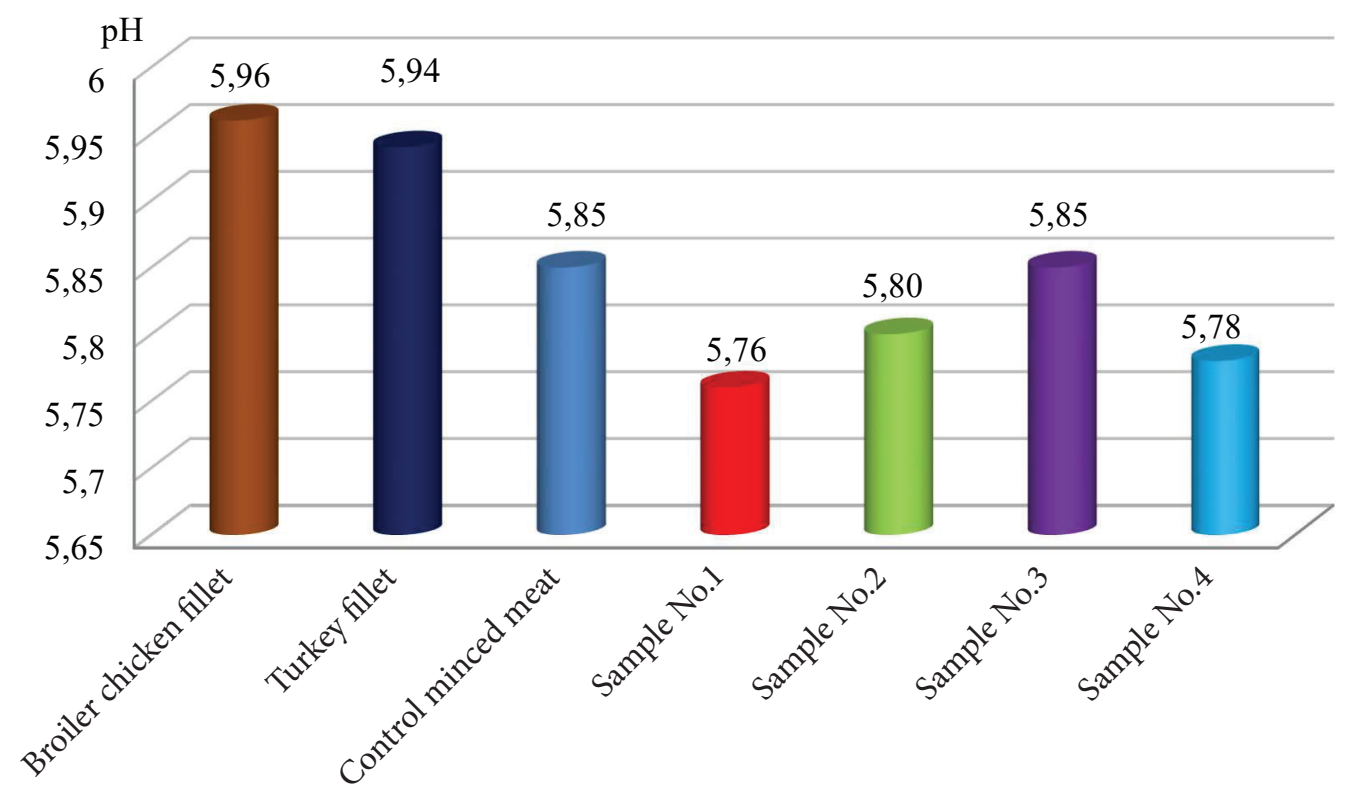

Figure 2. $\mathrm{pH}$ level in meat and minced meat

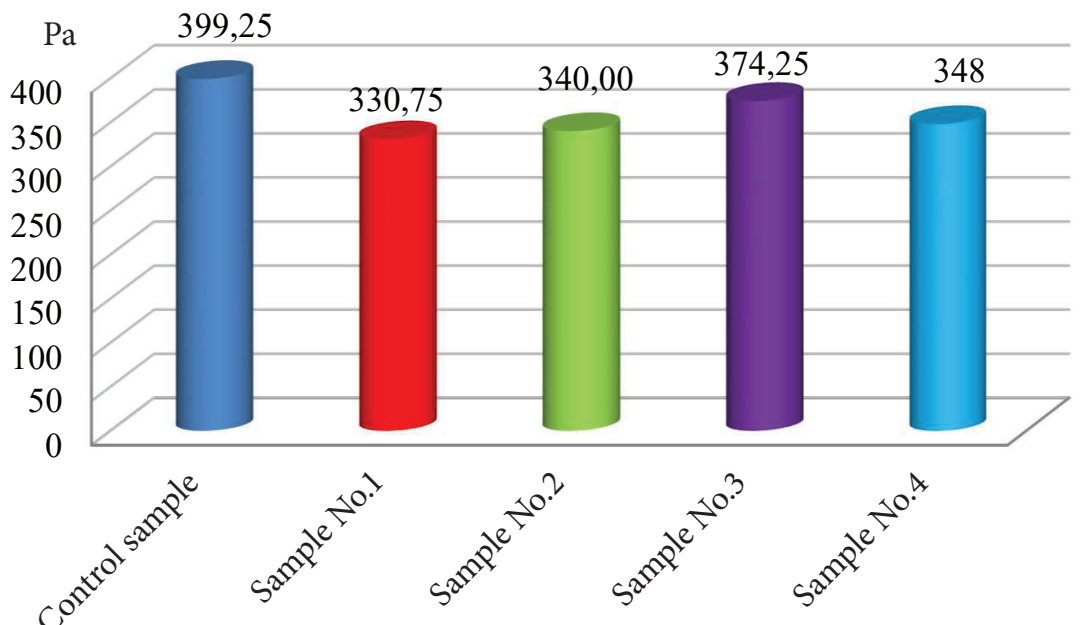

Figure 3. Adhesion of minced meat, $\mathrm{Pa}$ 
meat structure $(\mathrm{P}<0.001)$. The lowest viscosity level was in sample No.1 $(182.60 \pm 5.65 \mathrm{~Pa} \cdot \mathrm{s})$. This is significantly lower than in samples No.2 and No.4 by 62.8 and $60.8 \mathrm{~Pa} \cdot \mathrm{s}$, respectively $(\mathrm{P}<0.001)$, and in sample No.3 by $44.4 \mathrm{~Pa} \cdot \mathrm{s}$ $(\mathrm{P}<0.01)$. Addition of pork heart into the minced meat recipe imparted a loose structure to it (Figure 4).

The experimental samples of minced meat significantly exceeded the control sample by the level of water binding capacity (WBC) $(\mathrm{P}<0.001)$ (Figure 5). The authors [30] established that the use of ginger with the chicken breast as a model system facilitates water holding capacity, protein solubility, myofibril fragmentation, shear force reduction. A degree of myofibril fragmentation caused by the action of proteases in ginger is a technologically viable alternative to improve tenderness and yield of chicken breast. The data of our research confirm that addition of ginger in minced meat sample No.2 facilitated an increase in minced meat hydration by $15.12 \%$ compared to sample No.1, which recipe contained pork heart $(\mathrm{P}<0.01)$. Addition of cheese (sample No.3) and chicken liver (sample No.4) into the recipes led to a significant decrease in WBC compared to minced meat sample No.2, which composition included ginger $(\mathrm{P}<0.05)$.

Calculations of the moisture mass fraction in minced meat confirmed that the experimental samples exceeded the control by the moisture content $(\mathrm{P}<0.001)$ (Figure 6). The moisture mass fraction in the experimental samples was determined by the product recipe. Sample 2 contained more free moisture than sample No.1 by $5.06 \%(\mathrm{P}<0.01)$. The moisture mass fraction was $3.12 \%$ and $3.96 \%$ higher $(\mathrm{P}<0.01)$ in samples No.3 and No. 4 compared to sample No.1. Therefore, addition of ginger into minced meat recipes facilitated binding higher amounts of moisture of the hydrophilic groups compared to addition of cheese and chicken liver.

The $\mathrm{pH}$ value, moisture content and rheological characteristics were measured in the finished product after grilling for $15 \mathrm{~min}$. and following cooling (Figures 7, 8, 9).

Finished experimental samples had higher $\mathrm{pH}$ value than minced meat before thermal treatment. Significant differences between experiments were not found.

After grilling, the control sample retained the maximum values of ultimate shear stress (Figure 8 ).

Ultimate shear stress in the control sample was $300.73 \pm 25.63$, which was significantly higher by 160.6 and $162.39 \mathrm{~Pa}$ than in samples No.1 and No.4 $(\mathrm{P}<0.05)$ and by $134.23 \mathrm{~Pa}(\mathrm{P}<0.01)$ than in sample No.3. Sausages for grilling made from the control sample had stronger and more resilient consistency compared to the control samples.

Results of the moisture mass fraction measurement in the finished product are presented in Figure 9.

The highest value of the moisture mass fraction $(67.34 \%)$ was established in sample No.3 $(\mathrm{P}<0.01)$. A significant difference between samples No. 2 and No.3 by this indicator was not established. Moisture losses upon bringing to culinary preparedness were in a range from $35 \%$ in the control sample to $28 \%$ in the experimental samples.

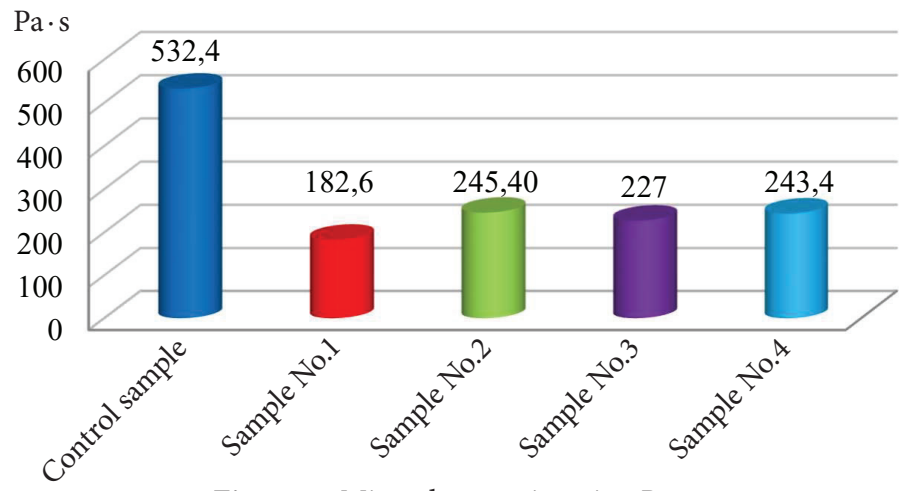

Figure 4. Minced meat viscosity, $\mathrm{Pa} \cdot \mathrm{s}$

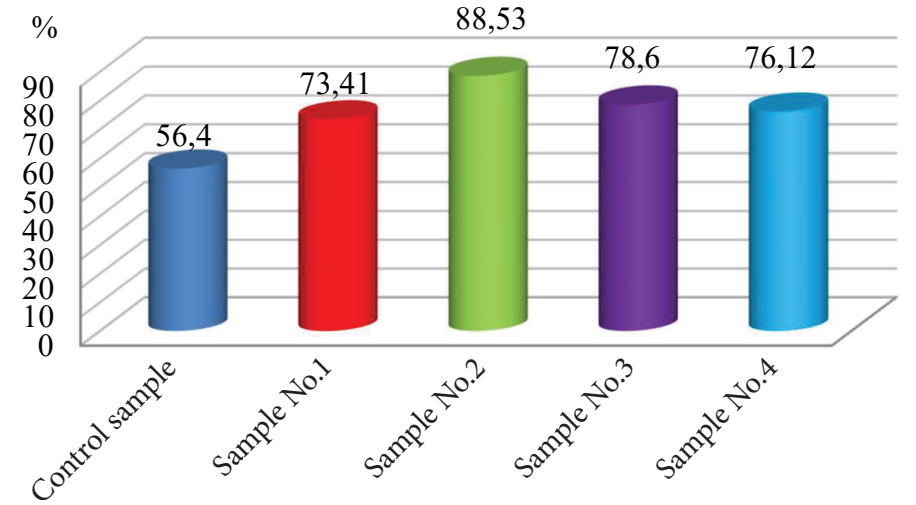

Figure 5. Water binding capacity of minced meat, $\%$

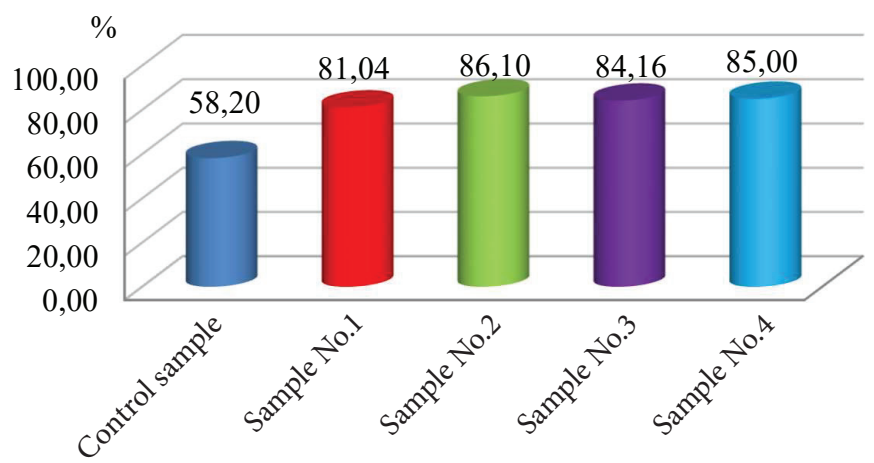

Figure 6. Moisture mass fraction in minced meat, \%

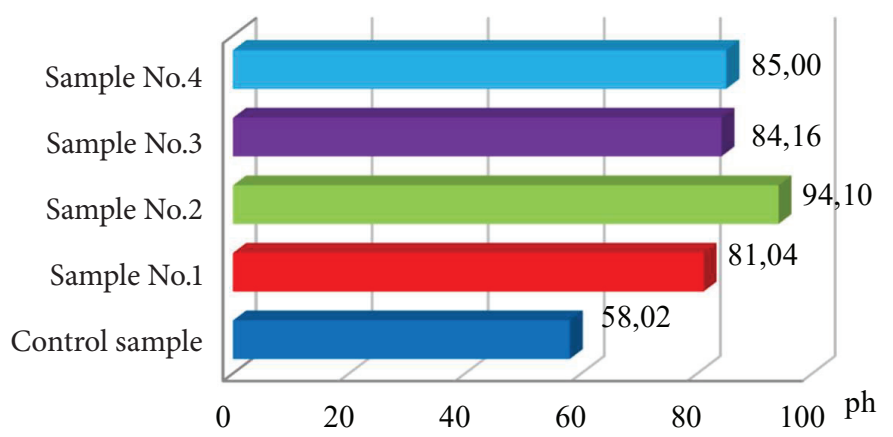

Figure 7. pH value in the finished product

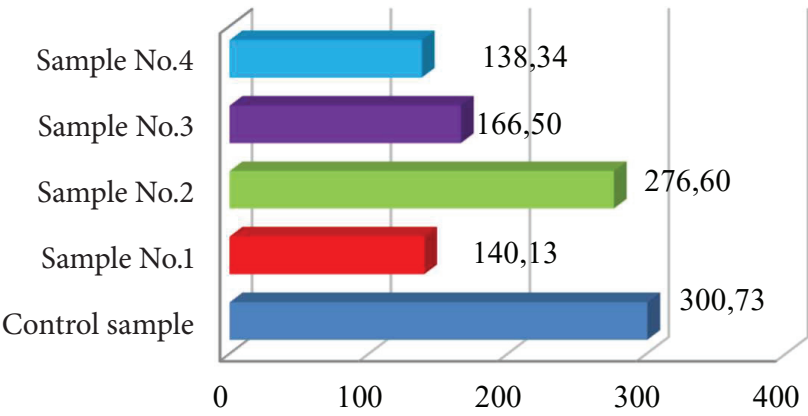

Figure 8. Ultimate shear stress in the finished products, $\mathrm{Pa}$ 


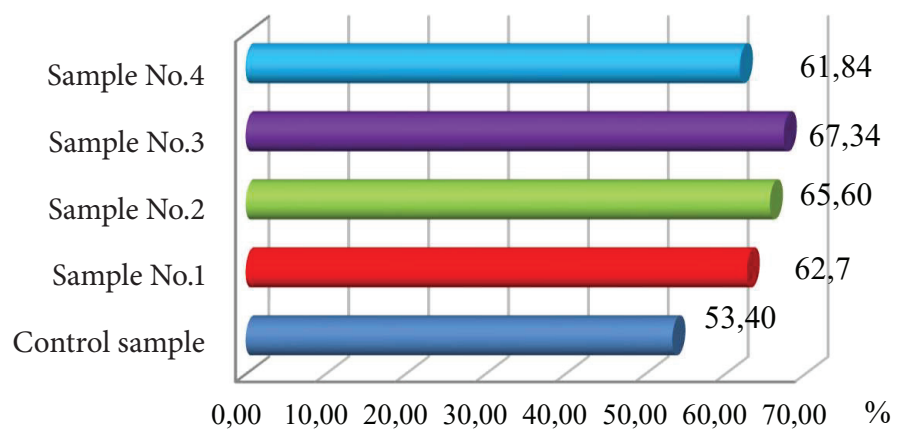

Figure 9. Moisture mass fraction in the finished product, $\%$

The technology for production of sausages for grilling includes the following main stages:

1. cutting chicken broiler and turkey carcasses according to the anatomical organization into leg quarters, breasts, thighs, drumsticks, carcasses, wings;

2. boning turkey thighs, turkey and broiler chicken breasts to obtain fillets

3. pork heart trimming of membranes and rough vessels, chicken liver trimming of membranes, washing under cold water;

4. sub-freezing of speck and pork belly at a temperature of $-12^{\circ} \mathrm{C}$;

5. cutting cheese into cubes with a size of $10 \times 10 \mathrm{~mm}$;

6. grinding meat raw materials in a grinder with a plate hole diameter of $8 \mathrm{~mm}$;

7. mixing meat raw materials in a sausage meat mixer with water in a volume of $20 \%$ and edible salt in an amount of $1 \mathrm{~kg}$ salt per $100 \mathrm{~kg}$ raw materials;

8. holding sausage meat for ageing at a temperature of $4{ }^{\circ} \mathrm{C}$ for 24 hours to create conditions in the finished products for formation of taste, juiciness, stickiness, increased resistance to the microbial action and water holding at thermal treatment;

9. making model sausage meat in a sausage meat mixer with the following addition and mixing of all required recipe components. At first, lean raw materials and spices were added; then, pork belly, dairy cream, chicken skin and speck preliminarily sub-frozen at a temperature of $-12^{\circ} \mathrm{C}$;

10. stuffing sausages for grilling into natural pig small intestine with a diameter of $40 \mathrm{~mm}$ using a vacuum syringe and making sausages with a length of $15 \mathrm{~cm}$;

11. hanging on the racks and holding at a temperature of $4^{\circ} \mathrm{C}$ for 6 hours for secondary structure formation in sausages, which corresponds to settling;

12. controlling semi-finished product quality; freezing to a temperature of $-8^{\circ} \mathrm{C}$;

13. packaging sausages into trays in the packaging machine under vacuum.

To assess finished product quality, the frozen semifinished product was grilled for $15 \mathrm{~min}$. The product core temperature was recorded at a level of $72{ }^{\circ} \mathrm{C}$ using a digital thermometer to guarantee that sausages from poultry meat were brought to culinary readiness. Wider possibilities of using the semi-finished product both frozen and thawed to a room temperature are recommended for a consumer. To bring a semi-finished product to culinary readiness, several methods are suggested: frying on a mangal, frying pan, grill, as well as baking both sides in a baking oven or microwave oven with a grill mode for $15 \mathrm{~min}$. to the goldbrownish color. Grilled sausages are preferably eaten hot. Sausages are served with a side dish, for example, backed potato, rice, buckwheat, fresh vegetables and greens; hot sauces (such as garlic, mustard, tomato sauces) are also suitable.

Methods for profile analysis allow quantitative assessment and graphical description of the whole spectrum of sensory properties of the meat product.

The profile method gives an opportunity to distinguish competitive products from each other by the individual peculiarities of taste, aroma and consistency. When evaluating an appearance of the sausages for grilling, the tasting panel paid attention to uniformity of grilling, tightness of the casing adherence to the surface of the presented samples, integrity of the casings. It was noted that this indicator corresponded to the norms in the control and experimental samples and did not have significant differences (Figure 10).

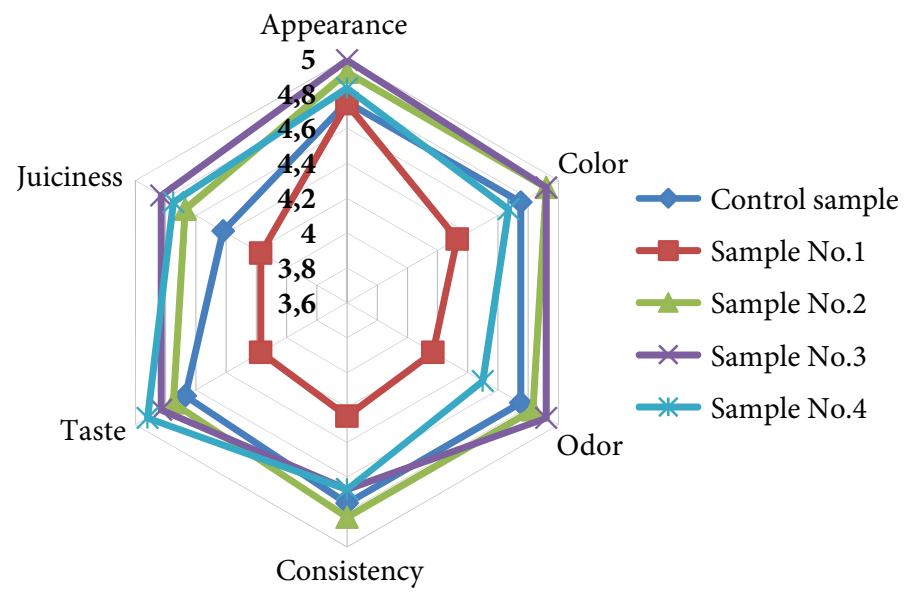

Figure 10. Values of the sensory indicators of the finished products, points

When evaluating color on the cut surface, the tasters noted a difference be-tween samples No. 1, 2 and 3. Samples No. 2 and No.3 exceeded sample No.1 by 11.8\% $(\mathrm{P}<0.05)$. According to the tasters' opinion, dark inclusions of the pork heart in sample No.1 caused the negative visual perception.

Evaluating product aroma, the taste panel noted that samples No.3 and No.4 exceeded sample No.1 by 0.75 and 0.33 points, respectively $(\mathrm{P}<0.01)$ or by $15 \%$ and $6.6 \%$. In sample No.3, odor was conditioned by introduction into the product recipe of semi-hard cheese, which was specially intended for grilling and imparted pronounced creammilk odor that was pleasant for the olfactory organs. In sample No.4, odor typical for liver was noticed, which was also very pleasant, delicate and hardly noticeable.

Properties of meat product texture influence human perception of finished product consistency. Textures, 
which are difficult to process in the mouth, are less preferable for people. Changes in meat product texture from juicer, softer and more uniform to harder and lumpy significantly reduce the consumption rate and energy intake, affect food behavior and, consequently, health [31].

Evaluating product consistency, the tasting panel observed the differences in samples No.1 and No.2. Sample No.2 exceeded sample No.1 $(\mathrm{P}<0.05)$ by 0.58 points or $11.6 \%$. Due to inclusion of heart, rough and crumbly consistency in sample No. 1 was conditioned by the by-product structure, which did not become tender even after thermal treatment. Firm and resilient consistency was noticed in sample No.2 as ginger can bind the minced meat structural components between themselves into the uniform monolithic structure. The significant differences were not found between all other experiments and the control; the samples corresponded to the requirements of the standard and had firm and homogeneous consistency.

In terms of taste, the experts preferred samples No. 2,3,4. Samples No.2 and No.3 exceeded sample No.1 by 0.58 and 0.66 or $11.6 \%$ and $13.2 \%$. In sample No.1, the specific flavor of pork heart was significantly different from astringent flavor of ginger and pungent flavor of cheese $\mathrm{P}<0.05$ ). Sample No.4 had more pronounced flavor of chicken liver compared to sample No.1 with inclusions of pork heart with a difference of 0.75 points or $15 \%(\mathrm{P}<0.01)$.

The experts noticed the highest juiciness in samples No.3 and No.4 compared to sample No.1 by 0.66 (13.2\%) $(\mathrm{P}<0.01)$ and 0.58 points or $11.6 \%(\mathrm{P}<0.05)$, respectively. Minced meat with cheese and chicken liver have the higher water holding capacity and can satisfy the consumer requirements in terms of finished product juiciness.

Statistical processing of all points showed that tasters preferred sample No.3, which exceeded the control sample and sample No.1 in terms of sensory characteristics by $0.28(\mathrm{P}<0.05)$ and 0.35 points $(\mathrm{P}<0.01)$. The second place was given to sample No. 4 , which exceeded the control sample and sample No.1 by 0.27 and 0.34 points $(\mathrm{P}<0.05)$. The third place was occupied by sample No.2, which exceeded sample No.1 by 0.33 points $(\mathrm{P}<0.05)$. Experimental samples of sausages for grilling with cheese, chicken liver and ginger turned to be more attractive by taste characteristics and all other sensory indicators than sausages with pork heart.

\section{Conclusion}

When evaluating color on the cut surface, the tasters noted a difference be-tween samples No. 1, 2 and 3. Samples No. 2 and No.3 exceeded sample No.1 by 11.8\% ( $\mathrm{P}<$ 0.05). According to the tasters' opinion, dark inclusions of the pork heart in sample No.1 caused the negative visual perception.

Evaluating product aroma, the taste panel noted that samples No.3 and No.4 exceeded sample No.1 by 0.75 and
0.33 points, respectively $(\mathrm{P}<0.01)$ or by $15 \%$ and $6.6 \%$. In sample No.3, odor was conditioned by introduction into the product recipe of semi-hard cheese, which was specially intended for grilling and imparted pronounced cream-milk odor that was pleasant for the olfactory organs. In sample No.4, odor typical for liver was noticed, which was also very pleasant, delicate and hardly noticeable.

Properties of meat product texture influence human perception of finished product consistency. Textures, which are difficult to process in the mouth, are less preferable for people. Changes in meat product texture from juicer, softer and more uniform to harder and lumpy significantly reduce the consumption rate and energy intake, affect food behavior and, consequently, health [31].

Evaluating product consistency, the tasting panel observed the differences in samples No.1 and No.2. Sample No. 2 exceeded sample No.1 $(\mathrm{P}<0.05)$ by 0.58 points or $11.6 \%$. Due to inclusion of heart, rough and crumbly consistency in sample No. 1 was conditioned by the by-product structure, which did not become tender even after thermal treatment. Firm and resilient consistency was noticed in sample No.2 as ginger can bind the minced meat structural components between themselves into the uniform monolithic structure. The significant differences were not found between all other experiments and the control; the samples corresponded to the requirements of the standard and had firm and homogeneous consistency.

In terms of taste, the experts preferred samples No. 2,3,4. Samples No.2 and No.3 exceeded sample No.1 by 0.58 and 0.66 or $11.6 \%$ and $13.2 \%$. In sample No.1, the specific flavor of pork heart was significantly different from astringent flavor of ginger and pungent flavor of cheese $\mathrm{P}<0.05$ ). Sample No.4 had more pronounced flavor of chicken liver compared to sample No.1 with inclusions of pork heart with a difference of 0.75 points or $15 \%(\mathrm{P}<0.01)$.

The experts noticed the highest juiciness in samples No.3 and No.4 compared to sample No.1 by 0.66 (13.2\%) $(\mathrm{P}<0.01)$ and 0.58 points or $11.6 \%(\mathrm{P}<0.05)$, respectively. Minced meat with cheese and chicken liver have the higher water holding capacity and can satisfy the consumer requirements in terms of finished product juiciness.

Statistical processing of all points showed that tasters preferred sample No.3, which exceeded the control sample and sample No.1 in terms of sensory characteristics by $0.28(\mathrm{P}<0.05)$ and 0.35 points $(\mathrm{P}<0.01)$. The second place was given to sample No. 4 , which exceeded the control sample and sample No.1 by 0.27 and 0.34 points $(\mathrm{P}<0.05)$. The third place was occupied by sample No.2, which exceeded sample No.1 by 0.33 points $(\mathrm{P}<0.05)$. Experimental samples of sausages for grilling with cheese, chicken liver and ginger turned to be more attractive by taste characteristics and all other sensory indicators than sausages with pork heart. 


\section{REFERENCES}

1. Warren, S. E., Bowker, B., Mohan, A. (2020). Physicochemical properties of beef tongue as a value-added meat product. Journal of Food Composition and Analysis, 88, Article 103433. https://doi. org/10.1016/j.jfca.2020.103433

2. Köppel, R., Ganeshan, A., Weber, S., Pietsch, K., Graf, C., Hochegger, R., et al. (2019). Duplex digital PCR for the determination of meat proportions of sausages containing meat from chicken, turkey, horse, cow, pig and sheep. European Food Research and Technology, 245(4), 853-862. https://doi.org/10.1007/s00217-018-3220-3

3. Tsaregorodtseva, E. V., Kabanova, T. V., Dolgorukova, M. V., Matveeva, E. L., Gugkaeva, M. S., Kornaeva, A. K., et al. (2020). Effect of preparation of the test samples by dissolution on the indicators of the protein composition of animal meat. International Journal of $R e$ search in Pharmaceutical Sciences, 11(2), 2283-2287. https://doi. org/10.26452/IJRPS.V1112.2196

4. Harastani, R., James, L. J., Walton, J., Woolley, E. (2020). Tackling obesity: A knowledge-base to enable industrial food reformulation. Innovative Food Science and Emerging Technologies, 64, Article 102433. https://doi.org/10.1016/j.ifset.2020.102433

5. Carvalho-Ferreira, J. P. D., da Cunha, D. T., Finlayson, G., Caldas, G., Jamar, G., Bandoni, D. H., (2020). Differential impact of consuming foods perceived to be high or low in fat on subsequent food reward. Food Quality and Preference, 85, Article 103977. https://doi. org/10.1016/j.foodqual.2020.103977

6. Rather, S. A., Masoodi, F. A., Rather, J. A., Gani, A., Wani, S. M., Ganaie, T. A., et al. (2021). Impact of thermal processing and storage on fatty acid composition and cholesterol oxidation of canned traditional low-fat meat product of India. LWT, 139, Article 110503. https://doi.org/10.1016/j.lwt.2020.110503

7. Naumenko, E.A., Semakova, V.V. (2017). Expanding the range of functional turkey meat semi-finished products. Trends in the development of science and education, 25-3, 19-21. https://doi. org/10.18411/lj-30-04-2017-3-04 (In Russian)

8. Gonotsky, V.A., Gonotskaya, V.A., Filipova, G.V., Derina, D.S. (2018). Ensuring the stability of the quality of chopped semi-finished products from meat and offal of musk ducks during storage. Poultry and poultry products, 6, 40-43. (In Russian)

9. Melro, E., Antunes, F., Cruz, I., Ramos, P. E., Carvalho, F., Alves, L. (2020). Morphological, textural and physico-chemical characterization of processed meat products during their shelf life. Food Structure, 26, Article 100164. https://doi.org/10.1016/j.foostr.2020.100164

10. Sabikun, N., Bakhsh, A., Ismail, I., Hwang, Y.-H., Rahman, M. S., Joo, S. -T. (2019). Changes in physicochemical characteristics and oxidative stability of pre- and post-rigor frozen chicken muscles during cold storage. Journal of Food Science and Technology, 56(11), 4809-4816. https://doi.org/10.1007/s13197-019-03941-0

11. Tsaregorodtseva, E.V. (2020). Experience in creating balanced minced meat. Vsyo o myase, 5S, 392-396. https://doi. org/10.21323/2071-2499-2020-5S-392-396 (In Russian)

12. Li, M., Li, Y., Wang, R., Wang, Y., Li, Y., Zhang, L. (2020). Effects of triglycerol monostearate on physical properties of recombined dairy cream. International Dairy Journal, 103, Article 104622. https://doi. org/10.1016/j.idairyj.2019.104622

13. Hansen, S. F., Petrat-Melin, B., Rasmusen, J. T., Larsen, L. B., Wiking, L. (2020). Impact of industrial cream heat treatments on the protein composition of the milk fat globule membrane. Journal of Dairy Research, 87(1), 89-93. https://doi.org/10.1017/ S0022029919000955

14. Tsaregorodtseva, E.V. (2014). The use of milk cream in the technology of meat products. Meat Industry, 4, 20-23. (In Russian)

15. Moradi, M., Omer, A. K., Razavi, R., Valipour, S., Guimarães, J. T. (2021). The relationship between milk somatic cell count and cheese production, quality and safety: A review. International Dairy Journal, 113, Article 104884. https://doi.org/10.1016/j.idairyj.2020.104884 16. Visconti, L. G., Rodríguez, M. S., Di Anibal, C. V. (2020). Determination of grated hard cheeses adulteration by near infrared spectroscopy (NIR) and multivariate analysis. International Dairy Journal, 104, Article 104647. https://doi.org/10.1016/j.idairyj.2020.104647

17. Giro, T. M., Berdnova, E. V., Aseeva, E. Y., Korsunov, V. P. (2021). Recipe design and study of quality characteristics of meat-vege- table semi-finished products for nutrition of patients with diabetes mellitus. Paper presented at the IOP Conference Series: Earth and Environmental Science, 640(3), Article 032036. https://doi. org/10.1088/1755-1315/640/3/032036

18. Salikhov, A. R., Salikhova, G. G., Konovalov, S. A., Mikolaychik, I. N., Morozova, L. A., Bazarnova, J. G. (2020). Meat minced semi-finished products with iodine-containing vegetable components. Paper presented at the IOP Conference Series: Earth and Environmental Science, 613(1), Article 012128. https://doi.org/10.1088/17551315/613/1/012128

19. Muhialdin, B. J., Kadum, H., Fathallah, S., Meor Hussin, A. S. (2020). Metabolomics profiling and antibacterial activity of fermented ginger paste extends the shelf life of chicken meat. LWT, 132, Article 109897. https://doi.org/10.1016/j.lwt.2020.109897

20. Mohammed, H. H. H., Ma, M., Elgasim, E. A., Jin, G., Jin, Y., Abdegadir, W. S., et al. (2020). Nitroso-hemoglobin-ginger conjugates effects on bacterial growth and color stability in a minced beef model. International Journal of Food Microbiology, 331, Article 108731. https://doi org/10.1016/j.ijfoodmicro.2020.108731

21. Lee, S. Y., Yim, D. G., Lee, D. Y., Kim, O. Y., Kang, H. J., Kim, H. S., et al. (2020). Overview of the effect of natural products on reduction of potential carcinogenic substances in meat products. Trends in Food Science and Technology, 99, 568-579. https://doi.org/10.1016/j. tifs.2020.03.034

22. Gantner, M., Brodowska, M., Horczyczak, E. G., Kalinowska, I. W., Najda, A., Pogorzelska, E., Godziszewska, J. (2018). Antioxidant effect of sage (salvia officinalis $L_{\text {.) }}$ extract on turkey meatballs packed in cold modified atmosphere. CYTA - Journal of Food, 16(1), 628-636. https://doi.org/10.1080/19476337.2018.1426632

23. Wen, C., Liu, Y., Ye, Y., Tao, Z., Cheng, Z., Wang, T., Zhou, Y. (2020). Effects of gingerols-rich extract of ginger on growth performance serum metabolites, meat quality and antioxidant activity of heatstressed broilers. Journal of Thermal Biology, 89, Article 102544. https://doi.org/10.1016/j.jtherbio.2020.102544

24. Johnson, R.A., Bhattacharyya, G.K. (2010). Statistics. Principles and methods, 6th ed. USA: John Wiley \& Sons, Inc. -706 p. ISBN 13 978-0-470-40927-5

25. Li, L., Bai, Y., Cai, R., Wu, C., Wang, P., Xu, X., Sun, J. (2018). Alkaline pH-dependent thermal aggregation of chicken breast myosin: Formation of soluble aggregates. CYTA - Journal of Food, 16(1), 765-775. https://doi.org/10.1080/19476337.2018.1470576

26. Mohammed, A. A., Zaki, R. S., Negm, E. A., Mahmoud, M. A., Cheng, H. W. (2021). Effects of dietary supplementation of a probiotic (bacillus subtilis) on bone mass and meat quality of broiler chickens. Poultry Science, 100(3), Article 100906. https://doi.org/10.1016/j. psj.2020.11.073

27. Parteca, S., Tonial, I. B., do Prado, N. V., da Trindade Alfaro, A. (2020). Electrical stunning parameters: Impact on the quality of turkey meat (meleagris gallopavo). Journal of Food Science and Technology, 57(7), 2612-2618. https://doi.org/10.1007/s13197-020-04297-6 28. Genccelep, H., Saricaoglu, F. T., Anil, M., Agar, B., Turhan, S. (2015). The effect of starch modification and concentration on steady-state and dynamic rheology of meat emulsions. Food Hydrocolloids, 48, 135-148. https://doi.org/10.1016/j.foodhyd.2015.02.002

29. Abu Zarim, N., Zainul Abidin, S., Ariffin, F. (2018). Rheological studies on the effect of different thickeners in texture-modified chicken rendang for individuals with dysphagia. Journal of Food Science and Technology, 55(11), 4522-4529. https://doi.org/10.1007/ s13197-018-3386-5

30. Cruz, P. L., Panno, P. H. C., Giannotti, J. D. G., Carvalho, R. V. D., Roberto, C. D. (2020). Effect of proteases from ginger rhizome on the fragmentation of myofibrils and tenderness of chicken breast. LWT, 120, Article 108921. https://doi.org/10.1016/j.Iwt.2019.108921

31. Laureati, M., Sandvik, P., L. Almli, V., Sandell, M., Zeinstra, G. G., Methven, L., et al. (2020). Individual differences in texture preferences among european children: Development and validation of the child food texture preference questionnaire (CFTPQ). Food Quality and Preference, 80, Article 103828. https://doi.org/10.1016/j. foodqual.2019.103828

\section{AUTHOR INFORMATION}

Elena. V. Tsaregorodtseva - candidat of agricultural sciences, docent, docent, Chair "Meat and dairy product technology", Mari State University. 1, Lenin Square, 424000, Yoshkar-Ola, Russia. Tel.: +7-902-739-85-94, E-mail: elena-zaregorodzewa@yandex.ru https://orcid.org/0000-0002-7715-5380

Completely prepared the manuscript and is responsible for plagiarism.

The author declare no conflict of interest. 